\title{
Recollections on Jean E. Rivier: A Giant in Neuroendocrinology
}

Last month saw the passing of Jean E. Rivier; a doyen of neuroendocrinology. He played a major part in the isolation and structural elucidation of $\mathrm{TRH}, \mathrm{GnRH}$, somatostatin, GHRH, CRF, and other biological regulatory peptides. Jean's contributions revolutionised the field of neuroendocrinology and set the scene for the development of novel therapeutics for diverse diseases - especially in cancer treatment.

In addition to these fundamental discoveries of the natural neuropeptides, Jean used his skills as a creative chemist to design and produce a plethora of analogues, many of which are in clinical practice today.

His generosity in supplying synthetic peptides to researchers throughout the globe played an immense role in advancing our understanding of the physiology and pathophysiology of almost every regulatory system in biomedicine.

I can think of no more apt description of Jean's contribution than the metaphor "dwarfs standing on the shoulders of giants" (Latin: nanos gigantum humeris insidentes) which expresses the notion of "discovering truth by building on previous discoveries," (Bernard of Chartres, 12th century), and later co-opted by Isaac Newton in 1675: "If I have seen further it is by standing on the shoulders of giants." Jean was a giant in neuroendocrinology on whose shoulders so many of us have stood.

\section{Robert P Millar,}

Editor in Chief, Neuroendocrinology Director, Centre for Neuroendocrinology, University of Pretoria, South Africa

Below is a link to an article by R. Scott Struthers, a student and close friend of Jean, which articulates these attributes in depth and which was published in Endocrine News, with permission. https://endocrinenews.endocrine.org/ remembering-jean-e-rivier-phd-1941-2019/ 